\section{Biomimetic Apatite-Based Functional Nanoparticles as Promising Newcomers in Nanomedicine: Overview of 10 Years of Initiatory Research}

\author{
Christophe Drouet ${ }^{1 *}$, Ahmed Al-Kattan ${ }^{1,2}$, Choimet $\mathbf{M}^{1,3}$, \\ Tourrette $A^{3}$, Santran $V^{4}$, Jeannette Dexpert-Ghys ${ }^{5}$, Bernard \\ Pipy $^{6}$, Brouillet $\mathrm{F}^{3}$ and Tourbin $\mathbf{M}^{7}$
}

\author{
${ }^{1}$ CIRIMAT Carnot Institute, UMR 5085 CNRS/INPT/UPS, University of \\ Toulouse, Ensiacet, Toulouse, France \\ 2LP3 Laboratory, UMR 6182 CNRS/Aix-Marseille University, Marseille, \\ France \\ ${ }^{3}$ CIRIMAT Carnot Institute, UMR 5085 CNRS/INPT/UPS, Faculty of \\ Pharmacy, University of Toulouse, Ensiacet, Toulouse, France \\ ${ }^{4}$ ICELLTIS Eurl, Immeuble Biostep, 436 rue Pierre et Marie Curie, 31670 \\ Labège, France \\ ${ }^{5}$ CEMES Laboratory, Toulouse, France \\ ${ }^{6}$ UMR-MD3 EA2405, University of Toulouse, France \\ ${ }^{7}$ LGC (Chemical Engineering Laboratory), UMR 5503 CNRS/INPT/UPS, \\ Ensiacet, University of Toulouse, France
}

\begin{abstract}
Biomimetic calcium phosphate apatites, analogous to bone mineral, may now be produced synthetically. Their intrinsic biocompatibility and the nanometer dimensions of their constitutive crystals not only allow one to envision applications in bone tissue regeneration, but also in other medical fields such as nanomedicine, and in particular in view of cell diagnosis.

In this mini-review, we look back at 10 years of our dedicated research, and summarize the main advances made in terms of preparation, physical-chemical characterizations and biological evaluations of colloidal formulations of biomimetic apatite-based nanoparticles, which we illustrate here with the angle of cancer diagnosis. The confirmed exceptional biocompatibility of these engineered nanoparticles, associated to the possibility to confer them luminescence properties by way of controlled lanthanide doping, and their capacity to be internalized by cells, including with
\end{abstract}

*Corresponding author: Christophe Drouet, CIRIMAT Carnot Institute, UMR 5085 CNRS/INPT/UPS, University of Toulouse, Ensiacet, 4 allee Emile Monso, 31030 Toulouse cedex 4, France, Tel: +33 534323411; E-mail: christophe.drouet@ensiacet.fr

Citation: Drouet C, Al-Kattan A, Choimet M, Tourrette A, Santran V, et al., (2015) Biomimetic Apatite-Based Functional Nanoparticles as Promising Newcomers in Nanomedicine: Overview of 10 Years of Initiatory Research. $\mathrm{J}$ intern Med Prim Healthcare 1: 001

Received: October 28, 2014; Accepted: February 06, 2015; Published: February 20, 2015 cancer cell addressing abilities (shown here as a proof of concept), underline that biomimetic apatite-based colloidal nanoparticles are particularly promising for nanomedicine applications, for example related to diseased cells diagnosis. Multidisciplinary research on these functional nanoparticles, initiated as described here, has now generated emulation in the scientific community where the concept of apatite nanoparticles for nanomedicine is being, gratifyingly, appropriated.

Keywords: Biomimetic apatites; Calcium phosphate; Cell diagnosis; Colloid; Luminescence; Medical imaging; Theranostic

\section{Introductive Statements}

Early and precise diagnosis plays a key role in successful patient's recovery. Thanks not only to exponential advances in the field of medical instrumentation but also that of nano-biotechnologies and the constant development and testing of new nano-systems, the limit of what is possible in terms of medical diagnosis is being continuously expanded [1]. The last decades have in particular witnessed the birth or development of various types of nano-systems for use in cell-based or tissue-based diagnosis. One can cite many examples, which includes but it not limited to gold nanoparticles, quantum dots, liposomes, silica, iron or gadolinium oxide nanoparticles [2-5]. In this regard, the domain of oncology has been rather pioneering; early and precise cancer diagnosis may indeed allow clinicians to propose adequate and anticipated therapy and to significantly reduce the odds of metastatic events [6]. An area attracting much attention in the oncology field relates to the search for nano-systems often denoted "nanoprobes" in the context of diagnosis capable of interacting with diseased cells or tissues, in a rather specific way, and thus is capable of identifying and locating tumoral regions in vivo and checking the efficacy of a therapeutic plan versus time.

In addition to cell or tissue specificity, via appropriate biomarkers, such nanoprobes should be intrinsically detectable by some way so as to track them within biological matter. In this regard, various characteristics of the nano-systems or nanoparticles can be exploited, typically such as luminescence, magnetism through Magnetic Resonance Imaging (MRI), or else radioactivity. A vast literature on nanoparticles developed for biomedical imaging is available; and listing all the existing systems under study is far beyond the scope of this paper. An overview of some of the most detailed systems is for example accessible in reference [7].

Other features are also expected from nanoprobes intended to be used in nanomedicine. In particular, the systems ought to exhibit a high biocompatibility ${ }^{1}$. Also, a growing attention is paid to the setup of versatile functional nanoparticles allowing multi-functionalization, e.g., associating simultaneously a cell targeting agent, a stabilizing agent for colloidal stabilization, a drug to be delivered intracellularly, etc., In the latter case, the nanoprobes initially intended for cell diagnosis then also become a drug-carrier, paving the way for theranostic approaches, coupling therapy and diagnosis [8-10].

$1-$ In this view, it may be remarked that the use of systems containing heavy metal ions such as cadmium could perhaps be further discussed. 
Taking into account all these aspects, the development of new types of nano-systems for nanomedicine, and in particular for cellular diagnosis, can only be encouraged. And in this view, the use of bio-inspired or even biomimetic compounds, mimicking compounds fabricated by nature itself, could serve as primary smart materials due to "advanced" biocompatibility properties. Among naturally occurring compounds observed in vivo in vertebrates such as humans, are calcium phosphate compounds exhibiting a crystalline structure called "apatite" [11]: bone and dentin tissues contain apatitic materials in the form of nanometer-sized crystals of a few tens of nanometers in length and up to about a tenth of nanometers in width. Apatite nanoparticles are thus already present in vertebrates - although in an agglomerated form and associated to collagen fibers - and the high surface reactivity of these nanocrystals is known to play a central role in the homeostasis of ionic and molecular species from body fluids. Apatite surface reactions like ionic exchanges and molecular adsorption/desorption processes help to maintain constant adequate concentrations for normal body functions $[12,13]$.

The physico-chemistry and reactivity of biomimetic nanocrystalline apatites has been investigated in previous works [14-23], including in review studies (eg: [11]). Briefly, it may be reminded that the apatite structure is quite accommodating and can accept many types of ionic substituents that confer additional properties to the apatitic nanocrystals. Also, the adsorptive potential of the surface of apatitic nanocrystals is quite large, which leads to a wider range of possibilities for association with many organic (bio) molecules. For example, surface grafting of enzymes [24], growth factors [25], anti-osteoporotic drugs [26,27], DNA [28], and so on have been studied previously. These wide adsorptive abilities and versatile ion accommodation capacity then make of bio-inspired nanocrystalline apatites an obvious platform for developing the armamentarium of biologists and clinicians, either in the field of bone reconstruction or - taking into account the intrinsically high biocompatibility of these bio-inspired systems - in other application fields such as nanomedicine, for diagnosis and/or therapy. Attempts to produce drug or antibody loaded nanoparticles of hydroxyapatite were reported $[29,30]$, but the absence of stabilizing agent in the preparation of hydroxyapatite nanosized crystals leaves a doubt concerning the stability of these particles in cell culture media or in vivo; as the use of an adsorbed dispersing agent on the surface of apatite nanoparticles appears as a prerequisite for preventing aggregation phenomena. The use of moleculeslikeDNAstrandshasbeen tempted, especially in view of transfection assays [31,32], but the presence of various negatively charged phosphate group along the whole backbone of DNA also allows one to wonder about long-term stability due to the potential creation of lateral molecular interactions or interaction with other (bio)molecules present in the medium.

In this article, we review 10 years of initiatory research on this field that we carried out in view of the setup and study of biomimetic apatite-based colloidal functional nanoparticles for nanomedicine, with a special focus here on cancer cell diagnosis. We recapitulate progresses made on i) the formulation of apatite colloids with individualized nanoparticles, ii) the study of some of their properties for a possible use as nanoprobes (including drying and re-suspending ability as well as the adjunction of luminescence properties), iii) the confirmation of their high biocompatibility, and iv) their use for cancer cell interaction by coupling the nanoparticles with a cell targeting agent. Promising application perspectives are underlined along the text, for functionalized nanoparticles based on biomimetic nanocrystalline apatites, especially in the context of nanomedicine.

\section{Materials and Methods}

\section{Preparation of apatite colloidal suspensions}

The protocol used for synthesizing apatite-based colloids was described previously [33]. All starting salts were at least of reagent-grade purity. Briefly three starting aqueous solutions were prepared: solution (A) containing a mixture of calcium and europium (or terbium) nitrates (Merck). The $\mathrm{Ln} /(\mathrm{Ca}+\mathrm{Ln})$ mole ratio, where $\mathrm{Ln}$ stands for the lanthanide ions used $\left(\mathrm{Eu}^{3+}\right.$ or $\left.\mathrm{Tb}^{3+}\right)$, was generally set to $2 \mathrm{~mol} \%$. The total $\mathrm{Ca}+\mathrm{Ln}$ amount in solution (A) was $4.87 \mathrm{mmol}$ dissolved in $6.25 \mathrm{ml}$ of deionized water. For purely calcic systems, neither europium nor terbium was added. The second solution, called (B), contained the stabilizing agent, namely 4.87 mmol of 2-Aminoethylphosphate (noted AEP), or $0.61 \mathrm{mmol}$ of phosphocholine chloride (calcium salt tetrahydrated, noted $\mathrm{PhCol}$ ), or $0.08 \mathrm{mmol}$ of Phosphonated Polyethylene Glycol ((PEG)P) at 5200 or at $5800 \mathrm{~g} / \mathrm{mol}$, dissolved in $12.5 \mathrm{ml}$ of deionized water. The AEP and PhCol were purchased at Sigma Aldrich and TCI Europe respectively. The (PEG)P polymers were prepared on-demand and purchased from the company SPECIFIC POLYMERS (Montpellier, France), Lot \# PEO Phosphonic acid SP-1P-1-001 [CAS. No. 91139195-2]. Finally solution (C) was composed of $1.62 \mathrm{mmol}$ of ammonium hydrogenphosphate (Prolabo VWR) dissolved in $6.25 \mathrm{ml}$ of deionized water. Solution (A) was added under stirring to solution (B), leading to the mixture (D) for which the $\mathrm{pH}$ was adjusted to 9.5. Then (D) was added into solution (C) for which the $\mathrm{pH}$ value was previously adjusted to 9.5. The suspension was then introduced in an oven preset at $100^{\circ} \mathrm{C}$, for $16 \mathrm{~h}$, for an ageing step. The colloidal suspensions obtained were then purified by dialysis process as detailed in ref. [34]. For biological testing, the final $\mathrm{pH}$ of the suspension was then reduced to the physiological value ( $\mathrm{pH} \sim 7.4$ ). For AEP-stabilized colloids, this was performed by addition of a solution of sodium Hexametaphosphate (HMP) at a concentration of $0.08 \mathrm{M}$, added until reaching a $\mathrm{pH}$ of 7.4. The methodology followed for the preparation of such colloids is summarized in figure 1 .

When mentioned in the text, Folic Acid (FA) was added in the reacting medium at the same time as the preparation of solution (A). The FA concentration used was typically $0.45 \mathrm{mM}$.

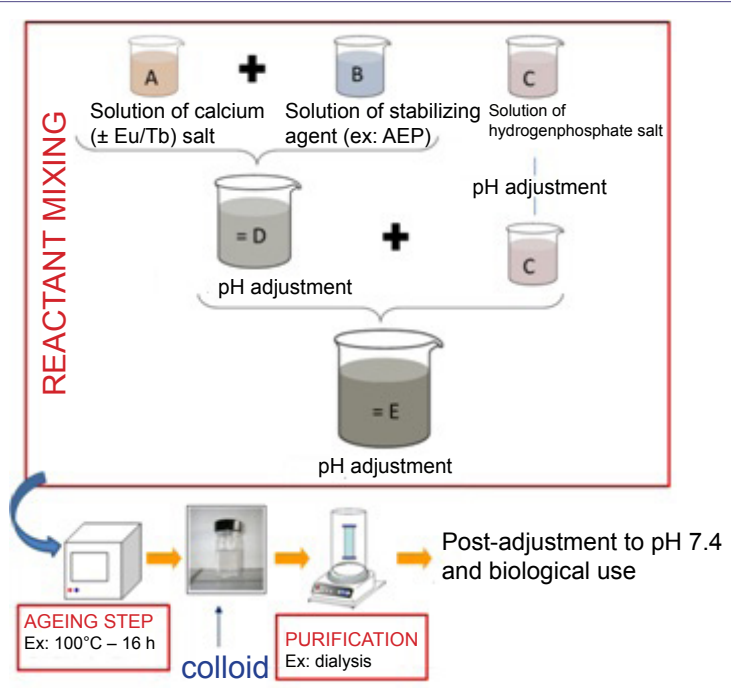

Figure 1: Synthesis methodology established for the preparation of apatite colloids. 
Freeze-drying was performed on a Christ Alpha 2-4 LD freeze dryer operating at $-80^{\circ} \mathrm{C}$ and less than $0.120 \mathrm{~m}$ bars of residual pressure. Spray drying experiments were run on a Buchimini Spray Dryer B 290 (Buchi, Germany). Briefly, the suspension was fed into the instrument by a peristaltic pump and sprayed with a $0.7 \mathrm{~mm}$ nozzle tip, by means of a flow of compressed air, in the drying chamber of the apparatus. A parallel flow of heated air aspirated induced the quick evaporation of water from the drops, leading to the formation and recovery of solid particles. The instrumental settings were the following: inlet temperature $\sim 105^{\circ} \mathrm{C}$, outlet temperature $\sim 60^{\circ} \mathrm{C}$, atomizing gas flow rate: $670 \mathrm{~L} / \mathrm{h}$, liquid flow rate: $1.8 \mathrm{ml} / \mathrm{min}$, aspirator power: $80 \%$, volume of suspension tested per experiment: $20 \mathrm{ml}$. When mentioned in the text, glucose was added to the medium prior to drying experiments. Typically, $150 \mathrm{mg}$ of glucose were added to $13.5 \mathrm{ml}$ of suspension. Re-dispersion in water of the dry composite apatite/glucose agglomerates formed upon drying was studied under moderate magnetic stirring ( $300 \mathrm{rpm}$ ).

\section{Physico-chemical characterizations}

The crystallographic structure of the nanoparticles was checked by X-Ray Diffraction (XRD) using a CPS 120 INEL diffractometer with the Kal cobalt radiation $(\lambda=1.78892 \AA)$. Fourier Transform Infrared (FTIR) analyses were performed, for additional characterization, using a Nicolet 5700 spectrometer operating in the $400-4000 \mathrm{~cm}^{-1}$ (resolution of $4 \mathrm{~cm}-1$ ).

Scanning Electron Microscopy (SEM) analyses were performed on a LEO VP135 microscope operated at $15 \mathrm{kV}$. Transmission Electron Microscopy (TEM) was run on a JEOL JEM-1011 microscope set at $100 \mathrm{keV}$.

The particle size of the colloids was determined without dilution by Dynamic Light Scattering (DLS) with a Zetasizer Nano ZS apparatus from Malvern Instruments $(\lambda=630 \mathrm{~nm})$. The dispersion of the data points was estimated to $0.5 \%$. The same apparatus was used for zeta potential measurements, using a capillary cell, by a combination of electrophoresis and Laser doppler velocimetry. Rheological measurements were carried out at $25^{\circ} \mathrm{C}$, using an $\mathrm{AR}$ rheometer (TA Instruments). The suspensions were analyzed by simple shear measurements using a parallel geometry (gap $1 \mathrm{~mm}$ ) with serrated plates (diameter $60 \mathrm{~mm}$ ). Experiments were realized in quadruplicate.

Luminescence properties were investigated using a Horiba Jobin Yvon Fluorolog 3-11 spectrofluorometer equipped with a $450 \mathrm{~W}$ xenon lamp. Excitation and emission were measured at room temperature directly on the colloidal suspensions, purified by dialysis. Concerning $\mathrm{Eu}^{3+}$, excitation spectra were recorded between $350 \mathrm{~nm}$ and $600 \mathrm{~nm}$ by monitoring the $\left[\mathrm{Eu}^{3+}{ }^{5} \mathrm{D}_{0} \rightarrow{ }^{7} \mathrm{~F}_{2}\right.$ emission at $\lambda_{\mathrm{em}}=612 \mathrm{~nm}$ (spectral bandwidth $=2 \mathrm{~nm}$ ). Emission spectra were recorded in the 500-700 $\mathrm{nm}$ range, with spectral bandwidth of $1 \mathrm{~nm}$, under selected excitation in the $\left[\mathrm{Eu}^{3+}\right]^{7} \mathrm{~F}_{0} \rightarrow{ }^{5} \mathrm{~L}_{6}$ of $\mathrm{Eu}^{3+}$ at $\lambda^{\mathrm{ex}}=392.8 \mathrm{~nm}$. For $\mathrm{Tb}^{3+}$, excitation spectra were recorded between $200 \mathrm{~nm}$ and $500 \mathrm{~nm}$ by monitoring the $\left[\mathrm{Tb}^{3+}\right]{ }^{5} \mathrm{D}_{4} \rightarrow{ }^{7} \mathrm{~F}_{5}$ emission at $\lambda_{\mathrm{em}}=540 \mathrm{~nm}$ (spectral bandwidth $=2 \mathrm{~nm}$ ). Emission of $\mathrm{Tb}^{3+}$ in the $410-700 \mathrm{~nm}$ range, with spectral bandwidth of $2 \mathrm{~nm}$, under selected excitation in the $\left[\mathrm{Tb}^{3+}\right]^{7} \mathrm{~F}_{6} \rightarrow{ }^{5} \mathrm{G}_{6}$ transition at $\lambda_{\text {ex }}=379 \mathrm{~nm}$. The transient characteristics of the emitting level ${ }^{5} \mathrm{D}_{4}$ and ${ }^{5} \mathrm{D}_{0}$ respectively of $\mathrm{Tb}^{3+}$ and $\mathrm{Eu}^{3+}$ were investigated with the phosphorimeter FL-1040, equipped with a UV xenon flash tube.
Emission decays were analyzed at chosen $\lambda_{\text {ex }}$ and $\lambda_{\text {em }}$ on a time interval up to $8 \mathrm{~ms}$. The analysis was made in quadruplicate. The time resolution imposed by the apparatus in the experimental conditions employed was $30 \mu \mathrm{s}$.

\section{Cytotoxicity and pro-inflammatory potential study}

The cytotoxicity of the colloids was assessed on the basis of MTT tests performed by the ICELLTIS Company (Labege, France) [35]. Two types of cells were used: human Adipose tissue Mesenchymal Stem Cells (AMSC) and breast cancer cells ZR-75-1, cultivated in humidified atmosphere with $5 \% \mathrm{CO}_{2}$ at $37^{\circ} \mathrm{C}$ in Dulbecco's Modified Eagle's Medium (DMEM) supplemented with $10 \%$ fetal bovine serum and $1 \%$ antibiotics (penicillin/streptomycin). The cells were placed in 96-well culture plates (30,000 cells per well) and each test was run in triplicate. After $24 \mathrm{~h}$ of preliminary incubation, the culture medium was replaced by fresh DMEM and the MTT tests were performed. Cell viability was assessed for various contact times over a period of 7 days, and 5 different concentrations of nanoparticles in the culture medium were tested: $0,0.1,1,2,5$ and $10 \mathrm{mg} / \mathrm{ml}$.

The pro-inflammatory potential of the colloidal nanoparticles was investigated by following their interaction with human monocyte cells $^{2}$ intended to mediate the inflammatory response to foreign substances. These cells are activated by inflammatory signals, conducing to an increased capacity to release pro-inflammatory and cytotoxic mediators such as Reactive Oxygen Intermediates (ROI) [36]. As indicated previously [35,37], the measure of the amount of possibly produced ROI was undergone by chemiluminescence: the generation of chemiluminescence was monitored continuously for 1 $\mathrm{h}$ after incubation of the cells with luminol $(66 \mathrm{mM})$ and after contact with the colloidal nanoparticles at various concentrations $(1.2,12,60$ and $120 \mu \mathrm{g} / \mathrm{ml})$. The experiments were run in triplicate. The negative control was based on experiments carried out without nanoparticles.

\section{Cell uptake evaluation}

Cell uptake of colloidal apatite-based nanoparticles was followed, for FA-functionalized or FA-free nanoparticles, on both ZR-75-1 (not over expressing folate receptors, FR) and on T-47-D (ATCC, cells over expressing folate receptors, $\mathrm{FR}^{+}$) breast cancer cells, for a concentration of nanoparticles in the culture medium of $1.5 \mathrm{mg} / \mathrm{ml}$. The negative control was carried out without nanoparticles. The tests, realized in triplicate, were carried out by the ICELLTIS Company (Labege, France). $24 \mathrm{~h}$ after seeding, the colloid was added to the cells during $24 \mathrm{~h}$. After washing in PBS buffer, the cells were then counted and centrifuged. The residual cell pellets were dissolved in $\mathrm{HCl} 37 \%$ and incubated for $30 \mathrm{~min}$ to allow quantification of the intracellular $\mathrm{Eu}$ and $\mathrm{Ca}$ contents by ICP-AES. The analyses were performed by the MARION TECHNOLOGIES Company, Verniolle, France, with a relative uncertainty of $3 \%$.

\section{Results and Discussion}

As stated in the introductive section, this work was based on the exploration, as a proof on concept, of the potential use of biomimetic apatite-based colloidal nanoparticles in the field of nanomedicine, and especially for cancer cell diagnosis. Below, the main findings related to this investigation have been listed, ranging from physico-chemical aspects up to biological aspects.

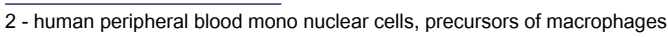




\section{Preparation of individualized nanoparticles by way of colloidal formulation}

Biomimetic apatitic compounds correspond roughly to the general chemical formula $\mathrm{Ca}_{10-\mathrm{x}}\left(\mathrm{PO}_{4}\right)_{6-\mathrm{x}}\left(\mathrm{HPO}_{4}\right)_{\mathrm{x}}(\mathrm{OH})_{2-\mathrm{x}}$, eventually substituted by either cations and/or anions. In bone [38] or in synthetic analogs prepared in conditions close to physiological ones [20], these compounds are comprised of nanocrystals. But their high specific surface area, their plate-like morphology and probably high surface energies give rise to a strong agglomeration effect between adjacent nanocrystals, leading to microcrystalline (or larger) aggregates. Moreover, this agglomeration process appears rather irreversible in practice. The large size of such aggregates, often larger than cells, constitutes a hurdle for use in nanomedicine applications. Ways to circumvent this drawback can be proposed, starting from the observation that the agglomeration process takes place as soon as precipitation is initiated in solution. Therefore, the control of the aggregation state of apatitic particles may be found by modifying the precipitation medium; and more precisely by adding in the solution a dispersing agent capable of i) adsorbing on the surface of apatite nanocrystals in formation and ii) of preventing/limiting the approach of adjacent nanocrystals by way of steric and/or electrostatic repulsion.

This hypothesis was tested by adding, in the precipitating medium, organic molecules exposing an anionic end-group such as phosphate or phosphonate groups likely to interact strongly with the $\mathrm{Ca}^{2+}$ ions located on the surface of the apatite nanocrystals. In this paper, we report on our experiments performed by adding either AEP, $\mathrm{PhCol}$, or (PEG)P in the medium (see details in the experimental section). Interestingly, in the presence of one of these molecules, a fluid suspension could be obtained in contrast to the experiment carried

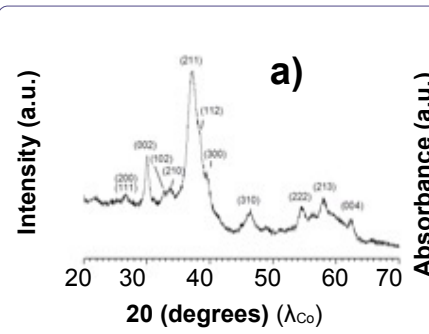

c)

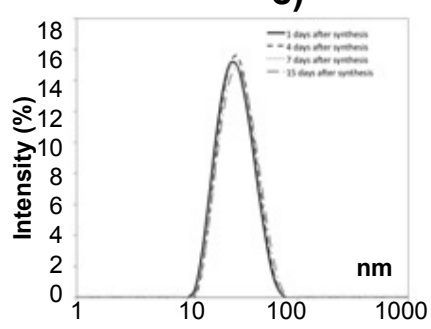

with AEP.
a) XRD pattern with apatite phase indexation of main peaks
b) FTIR spectrum
c) DLS particle size distribution (in nanometers)
d) TEM micrograph (reproduced with permission from reference [39])

out without additive. These three molecules may thus be considered as dispersing agents making it possible to prepare colloidal suspensions. The apatitic nature of the colloidal nanoparticles obtained in all these experiments was systematically confirmed: the obtained XRD pattern (Figure 2a) was characteristic of an apatite phase (indexation with the JCPDS file 09-432 relative to hydroxyapatite), and FTIR spectra corresponded to bone-like apatite with the presence of phosphate groups and associated water molecules, as well as typical absorption bands due to AEP (Figure 2b).

The colloidal-like aspect may be related to a distribution of the dispersing agent molecules around the particles, therefore hindering/limiting agglomeration between adjacent particles. In the case of AEP-stabilized colloids, for example, this matter of fact was indeed supported by zeta potential measurements pointing out a global positive surface charge (typically $+12 \mathrm{mV}$ ) due to the exposure of the $-\mathrm{NH}^{3+}$ terminal groups of AEP molecules, themselves interacting with exposed surface $\mathrm{Ca}^{2+}$ ions via their phosphate group. DLS analyses pointed out the nanometric dimensions of the colloidal particles, which followed monomodal particle size distributions dependent on experimental conditions (e.g., nature of dispersing agent used). Figure $2 c$, reports the typical case of an AEP-stabilized apatite colloid prepared aged 16 hours at $100^{\circ} \mathrm{C}$ and for an AEP/ Ca initial molar ratio of 1 . Table 1 , reports in a tabulated format the size characteristics ${ }^{3}$ of some of the colloidal nanoparticles obtained [40]. It may be noted that dimensions lower or around $100 \mathrm{~nm}$ were obtained for some of these suspensions, therefore opening perspectives in terms of nanoparticle/cells interaction in the field of nanomedicine where dimensions up to around $100 \mathrm{~nm}$ are often considered as optimal. In other cases, sizes larger than $100 \mathrm{~nm}$ were also obtained. Such variations show clearly the impact of the nature of stabilizing agent on the mean nanoparticle size obtained. For instance, in the case of (PEG) P-stabilized colloids, a significant decrease in particle size can be reached by increasing the PEG molecular weight (Table 1).

In particular, AEP-stabilized apatite colloids retained our attention due to nanoparticle sizes of the order of $30 \mathrm{~nm}$, also confirmed by direct analysis of the particles by TEM (Figure $2 \mathrm{~d}$ ). In this paper, the following sections will thus mostly focus on such AEP-stabilized apatite colloids; the highly biocompatible $e^{4}$ character of AEP being also particularly advantageous. The methodology followed for the preparation of such colloids was summarized in figure 1 [41]. Insights on the stability of such colloids were sought, by following the

\begin{tabular}{|l|c|c|l|}
\hline $\begin{array}{l}\text { Stabilizing agent } \\
\text { used in colloidal } \\
\text { formulation }\end{array}$ & $\begin{array}{l}\text { Typical } \\
\text { particle } \\
\text { size }\end{array}$ & Pdm $^{\star *}$ & Chemical formula \\
\hline PhCol & 70 & 0.112 & $\mathrm{~N}\left(\mathrm{CH}_{3}\right)_{3}{ }^{+}-\mathrm{CH}_{2}-\mathrm{CH}_{2}-\mathrm{O}-\mathrm{P}(\mathrm{O})\left(\mathrm{O}^{-}\right)_{2}$ \\
\hline$(\mathrm{PEG}) \mathrm{P} 5200 \mathrm{~g} / \mathrm{mol}$ & 200 & 0.225 & $\begin{array}{l}\mathrm{CH}_{3}-\mathrm{O}-\left[\mathrm{CH}_{2}-\mathrm{CH}_{2}-\mathrm{O}_{n}-\mathrm{CH}_{2}-\mathrm{CH}_{2-}\right. \\
\mathrm{CH}_{2}-\mathrm{P}(\mathrm{O})\left(\mathrm{O}^{-}\right)_{2}\end{array}$ \\
\hline$(\mathrm{PEG}) \mathrm{P} 5800 \mathrm{~g} / \mathrm{mol}$ & 120 & 0.156 & $\begin{array}{l}\mathrm{CH}_{3}-\mathrm{O}-\left[\mathrm{CH}_{2}-\mathrm{CH}_{2}-\mathrm{O}_{n}-\mathrm{CH}_{2}-\mathrm{CH}_{2-}\right. \\
\mathrm{CH}_{2}-\mathrm{P}(\mathrm{O})\left(\mathrm{O}^{-}\right)_{2}\end{array}$ \\
\hline AEP & 30 & 0.1 & $\mathrm{NH}_{3}+-\mathrm{CH}_{2}-\mathrm{CH}_{2}-\mathrm{O}-\mathrm{P}(\mathrm{O})\left(\mathrm{O}^{-}\right)_{2}$ \\
\hline
\end{tabular}

Table 1 : Main size characteristics of some colloidal formulations prepared with various stabilizing agents.

*Size corresponding to the maximum of the monodisperse domain (mode of the size distribution)

${ }^{* *}$ Polydispersity index (giving a measure of dispersion in size) 
possible evolution of their physical characteristics over colloid ageing time. Rheological characterization [39] pointed out the rheofluidifying behavior of such AEP/apatite colloids, witnessed by a nearly exponential decrease of the suspension viscosity upon increase of the shear rate, in the range 0.1 to $0.001 \mathrm{~Pa}$ s for shear rates varying from 0 and $300 \mathrm{~s}^{-1}$. Upon ageing over a 2-week period, a progressive increase of the suspension viscosity was detected, with an increased yield stress, evolving towards a threshold value close to $0.1 \mathrm{~Pa}$ However, interestingly, DLS measurements carried out $1,4,7$ and 15 days after synthesis indicated that the mean particle size (hydrodynamic diameter) remained rather unchanged and close to $30-35 \mathrm{~nm}$ over the whole period of colloid ageing. These results suggest that, despite some progressive structuration of the suspension over time at room temperature, no real agglomeration or sedimentation occurred and the nanoparticles size remained in the desired window for nanomedicine applications.

\section{Drying and re-dispersion of colloidal apatite nanoparticles}

From practical viewpoints, the manipulation of powder samples may be preferred to that of liquid suspensions, as in the case of some vaccine formulations for instance. In particular, the storage of powdered compounds over long periods of time is expected to be easier than that of fluid colloids. Also, other aspects such as sterilization processes may be found facilitated. For that reason, we also investigated the possibility to dry apatite-based colloids as presented above, while retaining the ability to re-suspend the nanoparticles in a subsequent step without loss of physico-chemical characteristics such as particle size.

It may be noted here that direct drying of apatite colloids without extra care leads to significant agglomeration, hardly reversible after re-immersion. This was linked to the high surface energy of apatite nanocrystals which are prone to interact strongly with each other upon elimination of water, to minimize the total surface energy of the system [39].

We then developed a strategy aiming at preserving the dispersibility of the nanoparticles, and based on the addition of a water-soluble matrix prior to the drying process. Experiments were here run by selecting glucose. Typically, $150 \mathrm{mg}$ of glucose were dissolved in the colloidal medium $(13.5 \mathrm{ml})$, and the system was then subjected to freeze-drying. In this case, re-suspension proved to be fully effective with an absence of sedimentation, and DLS experiments showed that no major change in particle size was detected as compared to the initial suspension purified by dialysis as exposed previously [34]. The advantageous role of glucose in this experiment can be explained, during the drying process, by the formation of a solid matrix preventing particle aggregation by a physical hindrance process. After re-immersion in aqueous medium, the solubilization of glucose then allows the release of the nanoparticles in the fluid.

The analysis by SEM (Figure 3a) of the freeze-dried glucose/apatite suspension suggested that the apatite nanoparticles were embedded within large glucose sheets of various dimensions and shapes. Although re-dispersion in aqueous medium was found to be efficient, the search for a better controlled morphology and size for the composite glucose/apatite was attempted with the objective of better controlling the re-dispersion kinetics. Noticeable progress was made by replacing the freeze-drying process by the spray drying technology. By using an inlet temperature of $\sim 105^{\circ} \mathrm{C}$ and outlet temperature of $60^{\circ} \mathrm{C}$, for example (see experimental section), the spray drying of AEP-stabilized colloidal suspensions led (with a yield estimated to $74 \%$ ) to the retrieval of purely spherical composite apatite/glucose particles (Figure 3b), with a monomodal size distribution centered around $1.2 \pm 0.9 \mu \mathrm{m}$. The re-dispersion was also found to be more effective and better controlled than with solely freeze-dried particles (Figure 3c).

\section{Conferring luminescence properties}

The possibility to confer luminescence to such apatite-based nanoparticles was studied for a possible use in the field of medical diagnosis through fluorescence imaging. Among the advantages of the apatite structure is its high capacity to accommodate foreign ions. In this work, the substitution, during apatite colloid synthesis, of part of the calcium $\mathrm{Ca}^{2+}$ ions by lanthanide ions such as europium $\left(\mathrm{Eu}^{3+}\right)$ and terbium $\left(\mathrm{Tb}^{3+}\right)$ ions was investigated, so as to render the nanoparticles luminescent respectively in the red and green domains of the visible light spectrum. Such ionic substitutions, at least up to 2 at $\%$ of $\mathrm{Eu}$ or $\mathrm{Tb}$ relative to the calcium content per apatite unit

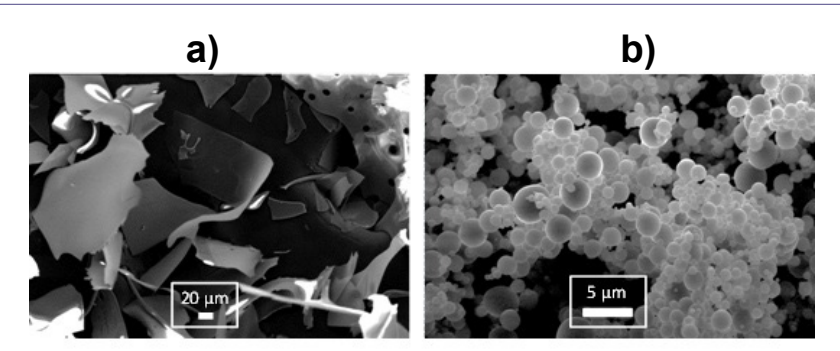

c)

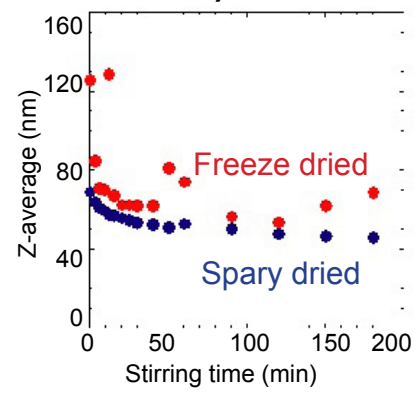

Figure 3: SEM micrographs for freeze-dried.

(a) Spray-dried

(b) AEP-stabilized biomimetic apatite suspensions enriched with glucose (hydrosoluble matrix)

(c) Re-dispersion kinetics in water at $25^{\circ} \mathrm{C}$

formula, were shown to be effective by the observation by XRD of a single apatite phase in each case. The substitution of divalent calcium by trivalent europium or terbium in the apatitic crystallographic array was discussed elsewhere in detail [33]; for non-stoichiometric apatites, several substitution scenarios can contribute to facilitate this process.

As could be expected, excitation and emission line characteristics of the luminescence behavior of $\mathrm{Eu}^{3+}$ or $\mathrm{Tb}^{3+}$ ions, respectively, were observed (Figure $4 \mathrm{a}$ and $4 \mathrm{~b}$ ). These have been described in previous occurrences $[33,42]$. Briefly, in the case of europium, main luminescence maxima (recorded under excitation at $393 \mathrm{~nm}$ ) were localized in

4 - AEP represents indeed the hydrophilic head of phosphatidylethanolamine, one type of phospholipids constitutive of cell membranes [41]

Volume $1 \cdot$ Issue $1 \cdot 100001$ 
the ranges 583-603, 605-627 and 685-715 $\mathrm{nm}$, assignable to the $\left[\mathrm{Eu}^{3+}\right]$ ${ }^{5} \mathrm{D}_{0} \rightarrow{ }^{7} \mathrm{~F}_{1},{ }^{5} \mathrm{D}_{0} \rightarrow{ }^{7} \mathrm{~F}_{2}$ and ${ }^{5} \mathrm{D}_{0} \rightarrow{ }^{7} \mathrm{~F}_{4}$ transitions. In the case of terbium, the emission spectrum (recorded under excitation at $379 \mathrm{~nm}$ ) showed peaks resulting from the $4 \mathrm{f}-4 \mathrm{f}$ transition of the $\mathrm{Tb}^{3+}$ ions: $\left[\mathrm{Tb}^{3+}\right]$ ${ }^{5} \mathrm{D}_{4} \rightarrow{ }^{7} \mathrm{~F}_{6}$ (at $488 \mathrm{~nm}$ ), ${ }^{5} \mathrm{D}_{4} \rightarrow{ }^{7} \mathrm{~F}_{5}$ (at $545 \mathrm{~nm}$ ), ${ }^{5} \mathrm{D}_{4} \rightarrow{ }^{7} \mathrm{~F}_{4}$ (at $586 \mathrm{~nm}$ ) and ${ }^{5} \mathrm{D}_{4} \rightarrow{ }^{7} \mathrm{~F}_{3}$ (at $623 \mathrm{~nm}$ ).

Beyond the low toxicity of $\mathrm{Eu}$ or $\mathrm{Tb}$ ions, another advantage of using these elements to convey luminescence lies in their long luminescence lifetime. This was investigated by following luminescence decay curves, over time [42]; the example of a colloid enriched with 2 at \%Eu (relative to $\mathrm{Ca}$ ) is given in figure $4 \mathrm{c}$, in logarithmic scale. For curves approximated to mono-exponential decay functions, the so-called "lifetime value" was found to reach $1.34 \pm 0.14 \mathrm{~ms}$ for $\mathrm{Eu}\left(\left[\mathrm{Eu}^{3+}\right]{ }^{5} \mathrm{D}_{0}\right)$ and $2.15 \pm 0.21 \mathrm{~ms}$ for $\mathrm{Tb}$ $\left(\left[\mathrm{Tb}^{3+}\right]{ }^{5} \mathrm{D}_{4}\right)$. These values, of the order of the millisecond, are noticeably larger than the luminescence lifetime of biological tissue auto-fluorescence, of the order of the nanosecond, thus enabling one to envision with such functional nanoparticles the analysis of biological materials over extended periods of time and/or the use of time-resolved luminescence equipment, e.g., for cell sorting. Intracellular diagnosis applications using colloidal apatite-based self-luminescent nanoparticles could therefore be seen as a promising approach.

Another study [43], on non-colloidal apatite, showed the possibility to visualize by laser scanning confocal microscopy some Eu-doped apatite particles internalized by human pancreatic cells Capan-1, exploiting their luminescence feature. The development of colloidal formulations, allowing a control of particle size and size distribution, is now expected to widen considerably the significance of the discovery/use of biomimetic apatite-based colloidal nanoparticles in the field of nanomedicine, and in particular for diseased cells diagnosis thanks to improved cell uptake capabilities. It may be noted

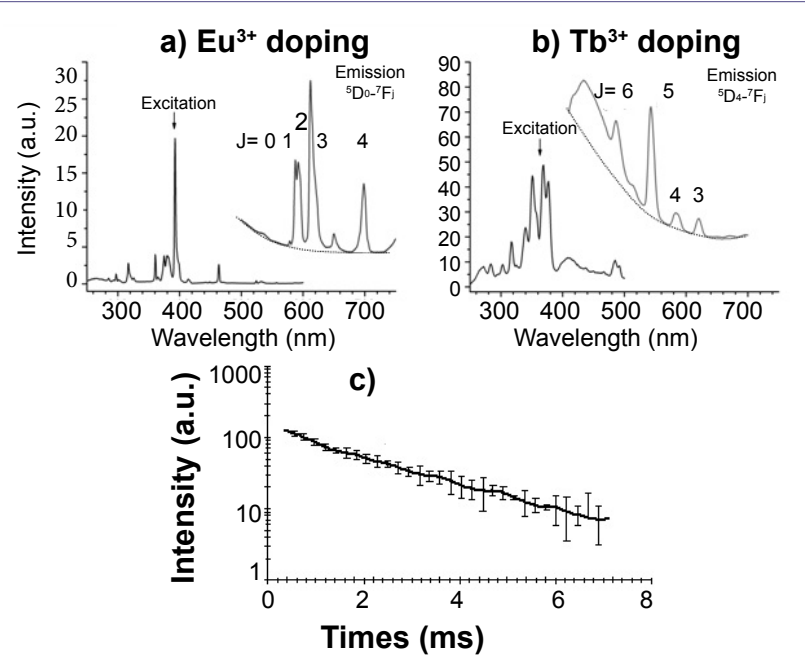

Figure 4: Excitation and emission characteristics.

a) Eu-doped

b) Tb-doped systems

c) luminescence lifetime of Eu-doped apatite colloid (2 at\% Eu relative to $\mathrm{Ca}$ ) reproduced in part from [42], with permission that, contrarily to organic luminescent probes which degrade rapidly due to the photo bleaching effect, the luminescence of these Eu- or $\mathrm{Tb}$-doped apatite nanoprobes is photo stable; also this luminescence feature can be obtained within or very close to the visible light domain, thus making them suitable for prolonged examination of live cells.

\section{Biocompatibility aspects}

Taking into account the nanomedicine applications envisioned for such apatite-based colloidal nanoparticles, and despite their intrinsic bio-inspired nature, it was important to point out on a quantitative manner their high cytocompatibility. This was carried out by introducing the colloidal nanoparticles to various types of cells [35]. In particular, MTT tests were run on adipose tissue mesenchymal stem cells, denoted AMSC, and human breast cancer cells ZR-75-1. Results indicated that cell viability remained close to $100 \%$, over 7 days of contact time, for concentrations of nanoparticles in the culture medium as high as $1 \mathrm{mg} / \mathrm{ml}$ for AMSC, and in the range $1-2 \mathrm{mg} / \mathrm{ml}$ for ZR-75-1 (Figure $5 \mathrm{a}$ ). Such levels of nanoparticle concentration are considered as particularly high, which thus points to the very low cytotoxicity of these colloidal nanoparticles.

Besides such direct cytotoxicity evaluations, it was also interesting to investigate the "pro-inflammatory potential" of these colloidal nanoparticles by checking the interaction with human monocytes [35]. To this aim, the amount of Reactive Oxygenated radical Intermediates (ROI) possibly produced by monocytes under inflammatory stress was followed by way of luminol-enhanced Chemiluminescence (CL). CL measurements performed after $1 \mathrm{hr}$ of contact between the colloidal nanoparticles ${ }^{5}$ purified by dialysis and stabilized at physiological $\mathrm{pH}$, and monocyte cells showed no significant effect (Figure 5b), whether activator or inhibitor, on the production of ROI, which remained at the level of the control ${ }^{6}$. These results thus suggested the absence of significant inflammatory response for such colloidal apatite nanoparticles.

\section{Cell uptake and targeting aspects}

The previous sections thus indicated the possibility to formulate fluid colloids containing individualized biomimetic apatite nanoparticles, with dimensions adapted to nanomedicine and interaction with cells; they also pointed out the high biocompatibility of these nanoparticles, as well as the possibility to make them luminescent, either red of green.

At this stage, it was thus appealing to go one step forward and follow cell uptake, from a quantitative point of view. Also, in the field of nanomedicine, the search for systems capable of addressing more specifically some types of diseased cells (e.g., cancer cells) are an important aspect. As a proof of concept of using such colloids for targeted/differential cell interaction, we functionalized the surface of our Eu-doped AEP-stabilized nanoparticles with folic acid, FA, via chemical adsorption. FA, or vitamin B9, is indeed known to be recognized more specifically by cells that over express folate receptors, $\mathrm{FR}$, as in the case of some ovary or breast cancers for instance $[44,45]$. The capacity for such FA-functionalized nanoparticles to be internalized by cells, most probably via endocytosis, was then followed on both T-47-D (over expressing folate receptors [46], or "FR'") and ZR-75-1 (without over expression [47], or "FR-") breast cancer cells. The extent of cell uptake was determined by measure by

5 - Nanoparticles concentration range studied: 0 - $120 \mu \mathrm{g} / \mathrm{ml}$

6 - Control experiment carried out in the absence of nanoparticles 


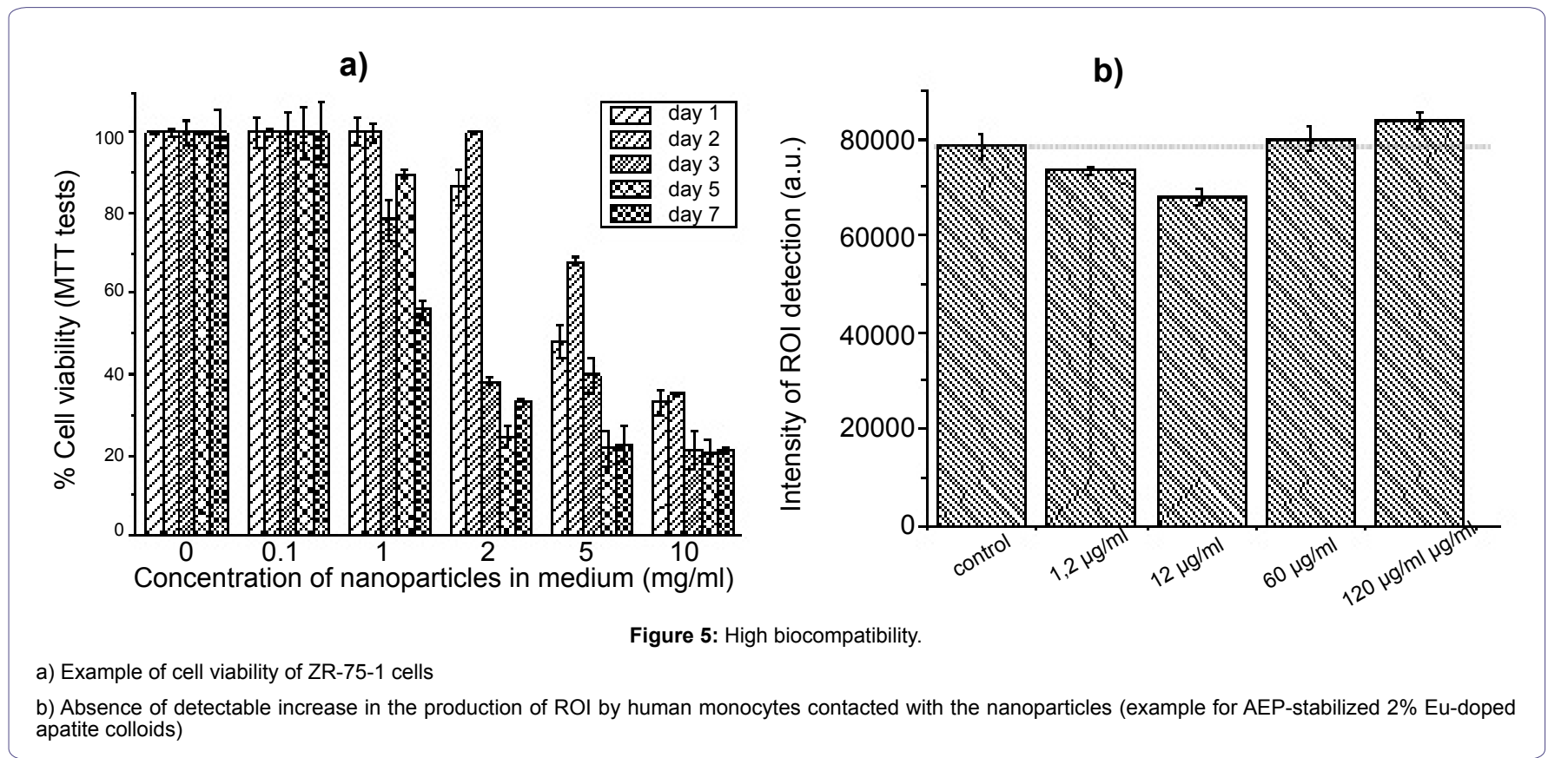

(ICP-AES) of the amount of calcium and europium ions in the cytoplasm after a contact time of 24 hours with the nanoparticles, functionalized or not with FA. No significant cell death was detected during this period. Control experiments carried out in the absence of nanoparticles in the medium recurrently showed a low intracellular calcium content $(<5 \mu \mathrm{g}$ per million cells) for both cell types as well as the absence of intracellular europium ions, as expected.

For cells contacted with nanoparticles without functionalization by folic acid (denoted "NP"), the analysis of intracellular $\mathrm{Ca}$ and Eu values indicated that both ZR-75-1 and T-47-D cells were able to internalize some "background" amount of nanoparticles ${ }^{7}$ but limited to $\mathrm{Ca} .20$ pmol of colloidal nanoparticles per million cells. On the contrary, the uptake of FA-grafted nanoparticles, denoted NP-FA, was significantly enhanced and especially for the $\mathrm{FR}^{+} \mathrm{T}-47-\mathrm{D}$ cells. It was found to be 3- to 4- fold greater than in the absence of FA functionalization, and cell uptake remained 1.5 to 2 times greater for T-47-D cells, reaching up to $86.2 \mathrm{pmol}$ of colloidal nanoparticles per million cells as compared to ZR-75-1 cells. These results unveil the more selective uptake of FA-modified apatite-based nanoparticles by the $\mathrm{FR}^{+}$-cell type, here represented by $\mathrm{T}-47-\mathrm{D}$ cells, therefore evidencing some targeting abilities for such colloidal engineered nanoparticles. These findings also allow us to envision even wider perspectives by substituting FA by other cell-targeting agents, so as to increase further the targeting selectivity and to adjust cell recognition capabilities of these colloidal nanoparticles to various cell types.

It may be mentioned here that Methotrexate (MTX), a chemotherapeutic drug, is an anti-folate compound with a chemical formula extremely close to that of folic acid. Adsorption experiments have shown the possibility to replace FA by MTX and to obtain MTX-functionalized apatites. This then opens not only perspectives in terms of cell diagnosis but also of therapeutics, using MTX for intracellular drug delivery. The era of theranostic thus also becomes within reach.

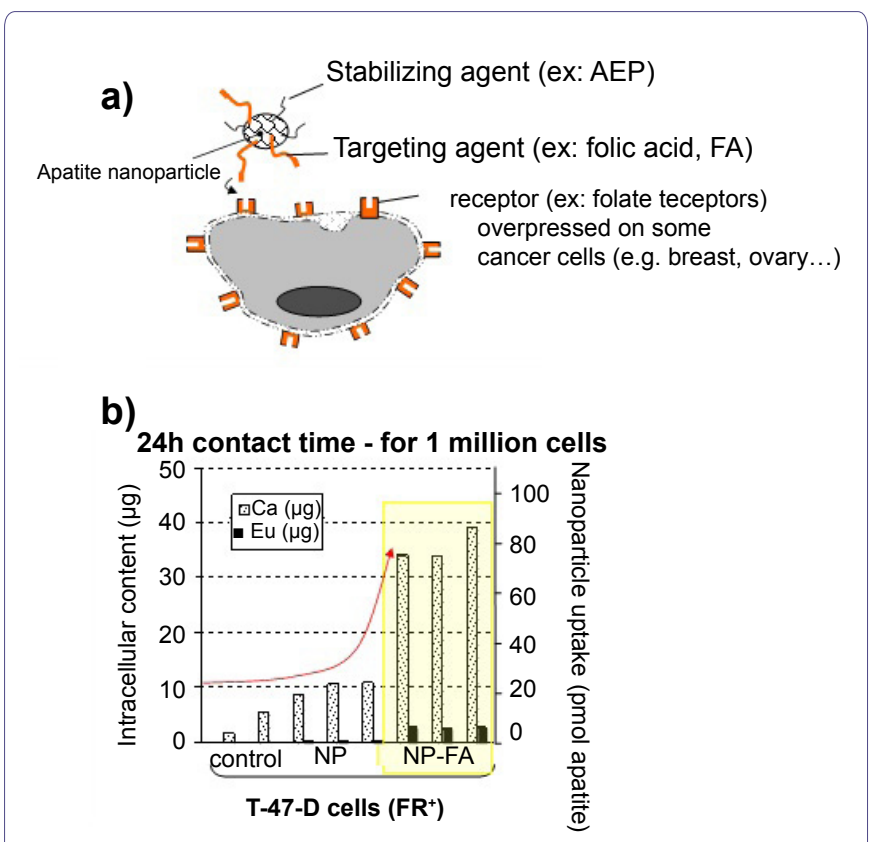

Figure 6: Cell uptake of apatite-based colloidal nanoparticles and targeting aspects.

a) Concept of nanoparticle/cell interaction

b) Addressing effect of folic acid functionalizationon T-47-D breast cancer cells (NP: raw colloidal nanoparticles; NP-FA: nanoparticles functionalized with folicacid)

\section{Concluding Remarks and Perspectives}

This mini-review came back on the main progresses that we made during last decade in terms of preparation and characterization of colloidal formulations of biomimetic apatites, the possibility to dry/re-suspend the nanoparticles while retaining their characteristics, 
Citation: Drouet C, Al-Kattan A, Choimet M, Tourrette A, Santran V, et al., (2015) Biomimetic Apatite-Based Functional Nanoparticles as Promising Newcomers in Nanomedicine: Overview of 10 Years of Initiatory Research. J intern Med Prim Healthcare 1:001.

and to confer them luminescence properties in variable colors, their high biocompatibility, and their cell uptake abilities with the eventuality of addressing more specifically some types of (cancer) cells, as is illustrated here by folic acid mediation as a proof of concept.

All these features may now allow one to envision promising perspectives in the use of such colloidal bio-inspired nanoparticles in the field of nanomedicine, and especially with the final aim of setting up point-of-care medical diagnosis solutions.

Some potential challenges or questions however still remain. For example, hematocompatibility and Foreign Body Response (FBR) will have to be investigated in more detail to get a wider evaluation of such systems, for example in view of intravenous administration. Also, stability studies on various colloidal formulations will have to be further explored, especially after contact with plasma proteins, as post-aggregation has to be prevented. Sterilization aspects will also have to be inspected more specifically. From a cell-targeting viewpoint, the necessity to increase the sensitivity of apatite-based nanoparticles to bio-markers of interest also represents an important challenge.

Multidisciplinary research on these inspiring functional nanoparticles, initiated as described in this mini-review, has undoubtedly started to create a great movement of interest from the "biomaterials" and "calcium phosphate" scientific communities, where the concept of apatite nanoparticles for nanomedicine is being contemplated and appropriated. Research on these systems is thus bound to continue more than ever, and extended worldwide, with the final objective of clinical diagnosis/therapeutic or else theranostic uses.

\section{References}

1. Moghimi SM, Hunter AC, Murray JC (2005) Nanomedicine: current status and future prospects. FASEB J 19: 311-330.

2. Bruchez M Jr, Moronne M, Gin P, Weiss S, Alivisatos AP (1998) Semiconductor nanocrystals as fluorescent biological labels. Science 281: 2013-2016.

3. Parak WJ, Gerion D, Pellegrino T, Zanchet D, Micheel C, et al. (2003) Biological applications of colloidal nanocrystals. Nanotechnology 14: 15-27.

4. Ow H, Larson DR, Srivastava M, Baird BA, Webb WW, et al. (2005) Bright and stable core-shell fluorescent silica nanoparticles. Nano Lett 5: 113-117.

5. Fizet J, Rivière C, Bridot JL, Charvet N, Louis C, et al. (2009) Multi-luminescent hybrid gadolinium oxide nanoparticles as potential cell labeling. $J$ Nanosci Nanotechnol 9: 5717-5725

6. Hamilton W, Neal RD, Stapley S (2014) Building the evidence base for the early symptomatic diagnosis of cancer (the ABC-DEEP Consortium - Workstream 3). Eur J Cancer Care 23: 7-7.

7. Bulte JWM, Modo MJ (2008) Introduction: The Emergence of Nanoparticles as Imaging Platform in Biomedicine. In: Bulte JM, Modo MJ (eds.). Nanoparticles in Biomedical Imaging, Fundamental Biomedical Technologies (Vol 102), Springer, New York, USA.

8. Prabhu P, Patravale V (2012) The upcoming field of theranostic nanomedicine: an overview. J Biomed Nanotechnol 8: 859-882.

9. Ahmed N, Fessi H, Elaissari A (2012) Theranostic applications of nanoparticles in cancer. Drug Discov Today 17: 928-934.

10. Choi KY, Liu G, Lee S, Chen X (2012) Theranostic nanoplatforms for simultaneous cancer imaging and therapy: current approaches and future perspectives. Nanoscale 4: 330-342.

11. Gomez-Morales J, lafisco M, Manuel Delgado-Lopez J, Sarda S, Drouet C (2013) Progress on the preparation of nanocrystalline apatites and surface characterization: Overview of fundamental and applied aspects. Progress in Crystal Growth and Characterization of Materials 59: 1-46.
12. Driessens FCM, Vandijk JWE, Verbeeck RMH (1986) The role of bone-mineral in calcium and phosphate homeostasis. Bulletin Des Societes Chimiques Belges 95: 337-342.

13. Bonjour JP (2011) Calcium and phosphate: a duet of ions playing for bone health. J Am Coll Nutr 30: 438-448.

14. Drouet C, Gómez-Morales J, lafisco M, Sarda S (2012) Calcium Phosphate Surface Tailoring Technologies for Drug Delivering and Tissue Engineering and applied aspects. In: Rimondini L, Bianchi CL, Vernè E (eds.). Surface Tailoring of Inorganic Materials for Biomedical Applications, Bentham Science Publishers, UAE.

15. Drouet C (2013) Apatite formation: why it may not work as planned, and how to conclusively identify apatite compounds. Biomed Res Int 2013: 490946.

16. Eichert D, Combes C, Drouet C, Rey C (2005) Formation and evolution of hydrated surface layers of apatites. Bioceramics 17: 3-6.

17. Eichert D, Drouet C, Sfihi H, Rey C, Combes C (2007) Nanocrystalline apatite-based biomaterials: Synthesis, Processing and Characterization. In: Kendall JB (ed.). Biomaterials Research Advances, Nova Science Publishers, USA. Pg: 93-143.

18. Rey C, Combes C, Drouet C, Lebugle V, Sfihi H, et al. (2007) Nanocrystalline apatites in biological systems: characterisation, structure and properties. Materialwissenschaft und Werkstofftechnik 38: 996-1002.

19. Rey C, Combes C, Drouet C, Sfihi H, Barroug A (2007) Physico-chemical properties of nanocrystalline apatites: Implications for biominerals and biomaterials. Materials Science and engineering : C 27: 198-205.

20. Vandecandelaere N, Rey C, Drouet C (2012) Biomimetic apatite-based biomaterials: on the critical impact of synthesis and post-synthesis parameters. J Mater Sci Mater Med 23: 2593-2606.

21. Delgado-López JM, lafisco M, Rodríguez I, Tampieri A, Prat M, et al. (2012) Crystallization of bioinspired citrate-functionalized nanoapatite with tailored carbonate content. Acta Biomater 8: 3491-3499.

22. lafisco M, Delgado-López JM, Gómez-Morales J, Hernández-Hernández MA Rodríguez-Ruiz I, et al. (2011) Formation of calcium phosphates by vapour diffusion in highly concentrated ionic micro-droplets. Crystal Research and Technology 46: 841-846.

23. Sakhno Y, Bertinetti L, lafisco M, Tampieri A, Roveri N, et al. (2010) Surface Hydration and Cationic Sites of Nanohydroxyapatites with Amorphous or Crystalline Surfaces: A Comparative Study. J Phys Chem C 114: 1664016648.

24. Weber CG, Mueller M, Vandecandelaere N, Trick I, Burger-Kentischer A, et al. (2014) Enzyme-functionalized biomimetic apatites: concept and perspectives in view of innovative medical approaches. J Mater Sci Mater Med 25: 595-606.

25. Autefage $H$, Briand-Mésange $F$, Cazalbou $S$, Drouet $C$, Fourmy $D$, et al (2009) Adsorption and Release of BMP-2 on Nanocrystalline Apatite-Coated and Uncoated Hydroxyapatite/beta-Tricalcium Phosphate Porous Ceramics. J Biomed Mater Res B Appl Biomater 91: 706-715.

26. Al-Kattan A, Errassifi F, Sautereau AM, Sarda S, Dufour P, et al. (2010) Medical Potentialities of Biomimetic Apatites through Adsorption, Ionic Substitution, and Mineral/Organic Associations: Three Illustrative Examples. Adv Eng Mater 12: 224-233

27. Errassifi F, Sarda S, Barroug A, Legrouri A, Sfihi H, et al. (2014) Infrared, Raman and NMR investigations of risedronate adsorption on nanocrystalline apatites. J Colloid Interface Sci 420: 101-111.

28. Grunenwald A, Keyserb C, Sautereaua AM, Crubézyc E, Ludesbet B et al. (2014) Adsorption of DNA on biomimetic apatites: Toward the understanding of the role of bone and tooth mineral on the preservation of ancient DNA. Appl Surf Sci 292: 867-875.

29. Ong HT, Loo JSC, Boey FYC, Russell SJ, Ma J, et al. (2008) Exploiting the high-affinity phosphonate-hydroxyapatite nanoparticle interaction for delivery of radiation and drugs. J Nanopart Res 10: 141-150. 
30. lafisco M, Delgado-Lopez JM, Varoni EM, Tampieri A, Rimondini L, et al. (2013) Cell surface receptor targeted biomimetic apatite nanocrystals for cancer therapy. Small 9: 3834-3844.

31. Mondejar SP, Kovtun A, Epple M (2007) Lanthanide-doped calcium phosphate nanoparticles with high internal crystallinity and with a shell of DNA as fluorescent probes in cell experiments. J Mater Chem 17: 4153-4159.

32. Welzel T, Radtke I, Meyer-Zaika W, Heumann R, Epple M (2004) Transfection of cells with custom-made calcium phosphate nanoparticles coated with DNA. J Mater Chem 14: 2213-2217.

33. Al-Kattan A, Dufour P, Dexpert-Ghys J, Drouet C (2010) Preparation and Physicochemical Characteristics of Luminescent Apatite-Based Colloids. J Phy Chem C 114: 2918-2924.

34. Al-Kattan A, Dufour P, Drouet C (2011) Purification of biomimetic apatite-based hybrid colloids intended for biomedical applications: A dialysis study. Colloids Surf B Biointerfaces 82: 378-384.

35. Al-Kattan A, Girod-Fullana S, Charvillat C, Ternet-Fontebasso H, Dufour P, et al. (2012) Biomimetic nanocrystalline apatites: Emerging perspectives in cancer diagnosis and treatment. Int J Pharm 423: 26-36.

36. Laskin DL, Laskin JD (2001) Role of macrophages and inflammatory mediators in chemically induced toxicity. Toxicology 160: 111-118.

37. Lefèvre L, Galès A, Olagnier D, Bernad J, Perez L, et al. (2010) PPARy ligands switched high fat diet-induced macrophage M2b polarization toward M2a thereby improving intestinal Candida elimination. PLoS One 5: 12828.

38. Rey C, Combes C, Drouet C, Glimcher MJ (2009) Bone mineral: update on chemical composition and structure. Osteoporos Int 20: 1013-1021.

39. Tourbin M, Al-Kattan A, Drouet C (2014) Study on the stability of suspensions based on biomimetic apatites aimed at biomedical applications. Powder Technol 255: 17-22.
40. Bouladjine A, Al-Kattan A, Dufour P, Drouet C (2009) New advances in nanocrystalline apatite colloids intended for cellular drug delivery. Langmuir 25 : 12256-12265.

41. Rothfield L, Finkelstein A (1968) Membrane biochemistry. Annu Rev Biochem 37: 463-496.

42. Al-Kattan A, Santran V, Dufour P, Dexpert-Ghys J, Drouet C (2014) Novel contributions on luminescent apatite-based colloids intended for medical imaging. J Biomater Appl 28: 697-707.

43. Doat A, Fanjul M, Pellé F, Hollande E, Lebugle A (2003) Europium-doped bioapatite: a new photostable biological probe, internalizable by human cells. Biomaterials 24: 3365-3371.

44. Antony AC (1992) The biological chemistry of folate receptors. Blood 79: 2807-2820.

45. Spinella MJ, Brigle KE, Sierra EE, Goldman ID (1995) Distinguishing between folate receptor-alpha-mediated transport and reduced folate carrier-mediated transport in L1210 leukemia cells. J Biol Chem 270: 7842-7849.

46. Geszke M, Murias M, Balan L, Medjahdi G, Korczynski J, et al. (2011) Folic acid-conjugated core/shell $\mathrm{ZnS}: \mathrm{Mn} / \mathrm{ZnS}$ quantum dots as targeted probes for two photon fluorescence imaging of cancer cells. Acta Biomater 7: 13271338.

47. Dixon KH, Mulligan T, Chung KN, Elwood PC, Cowan KH (1992) Effects of folate receptor expression following stable transfection into wild type and methotrexate transport-deficient ZR-75-1 human breast cancer cells. J Biol Chem 267: 24140-24147. 